(2) Open Access Full Text Article

\title{
A prospective pilot study comparing combined intravitreal ranibizumab and half-fluence photodynamic therapy with ranibizumab monotherapy in the treatment of neovascular age-related macular degeneration
}

This article was published in the following Dove Press journal:

Clinical Ophthalmology

14 September 2012

Number of times this article has been viewed

\author{
Patrick D Williams' \\ David Callanan' \\ Wayne Solley' \\ Robert L Avery ${ }^{2}$ \\ Dante J Pieramici² \\ Tom Aaberg ${ }^{3}$ \\ 'Texas Retina Associates, Dallas, TX, \\ ${ }^{2}$ California Retina Consultants and \\ Research Foundation, Santa Barbara, \\ CA, ${ }^{3}$ Retinal Associates, Grand Rapids, \\ MI, USA
}

Correspondence: Tom Aaberg Jr Retinal Associates, 2757 Leonard St. Grand Rapids MI 49525, USA

Tel + I 6169542020

Email thomasaaberg@comcast.net
Purpose: This prospective multi-center pilot study compares the use of half-fluence photodynamic therapy combined with ranibizumab with ranibizumab monotherapy for the treatment of neovascular age-related macular degeneration.

Methods: All patients presenting with untreated subfoveal neovascular age-related macular degeneration were considered for inclusion. Patients were randomized to receive either ranibizumab with half-fluence photodynamic therapy or ranibizumab alone. Patients in the ranibizumab alone group were given three consecutive monthly ranibizumab injections and were followed monthly. They were treated with ranibizumab as needed, based on clinical discretion, using vision and optical coherence tomography. Patients in the combined group were given one same-day combined ranibizumab and half-fluence $\left(25 \mathrm{j} / \mathrm{cm}^{2}\right)$ photodynamic therapy treatment and were treated monthly as needed. Outcomes included changes in standardized visual acuity, optical coherence tomography foveal thickness, and percentage of as-needed injections to maintenance examinations.

Results: Fifty-six out of 60 enrolled patients completed the twelve month primary outcome visit; this consisted of 27 patients receiving ranibizumab alone and 29 receiving combined treatment. The average age was 79.1 for the ranibizumab alone group and 79.3 for the combined group. The mean visual acuity in the ranibizumab alone group improved from 52.9 Early Treatment of Diabetic Retinopathy letters initially to 62.8 letters at twelve months. The mean visual acuity in the combined group improved from 49.2 letters to 51.8 letters at twelve months. The differences in visual acuity improvements were not statistically significant based on a two-tailed $t$-test $(P=0.2)$. Due to the presence of outliers in each group, a Mann-Whitney $U$ test was performed to confirm the results $(\mathrm{U}=325 ; P=0.28)$. The mean optical coherence tomography foveal thickness improved 92.5 microns and 106.7 microns in the ranibizumab alone and the combined group, respectively. The difference was not significant based on a two-tailed $t$-test $(P=0.6)$. The ranibizumab alone group received an average of 6.8 injections, while the combined group received an average of three injections. This difference was not significant based on a chi-square test $(P=0.11)$.

Conclusion: The groups appeared similar based on statistical analysis, but larger studies are needed to determine possible small differences between combination therapy and monotherapy.

Keywords: ranibizumab, macular degeneration, photodynamic therapy, verteporfin, choroidal neovascularization, anti-vegf 


\section{Introduction}

Anti-angiogenic therapy has redefined the treatment of wet agerelated macular degeneration (AMD), and ranibizumab and bevacizumab are currently the standard of care for wet AMD. The phase III trials demonstrating the benefit of ranibizumab used a fixed, monthly dosing regimen. ${ }^{1,2}$ However, monthly dosing regimens can be costly and time consuming for both patients and their families. Each intravitreal injection also carries the risk of endophthalmitis. ${ }^{3}$ Because of the expense and time involved with monthly treatments, many practitioners elect to use variable re-treatment regimens. The goal of such regimens is to maintain the same visual benefit as monthly dosing while easing the cost and time burden on patients and families. The PIER study showed that close monitoring and timely re-treatment are still necessary to maintain the initial visual benefit. ${ }^{4}$ The PrONTO study suggested, however, that a pro re nata (PRN) approach to re-treatment could meet the goal of visual maintenance while easing the treatment burden. ${ }^{5,6}$ The ideal maintenance regimen is still an area of scientific debate.

Photodynamic therapy (PDT) with verteporfin has a demonstrated benefit for predominantly classic wet AMD. ${ }^{7,8}$ Clinical trials have shown that anti-angiogenic agents are superior to PDT as monotherapy. ${ }^{910}$ Because PDT has a separate mechanism of action however, it may have an additive effect for wet AMD in combination with anti-angiogenic agents. Unfortunately, standard-fluence PDT can have deleterious effects on the normal vascular architecture with resultant vision loss. ${ }^{9}$ In contrast, reduced-fluence PDT seems to have a similar effect on pathologic vessels while reducing the damage to normal tissues. ${ }^{10}$ For this reason, many practitioners have adopted the use of reduced-fluence PDT instead of standard-fluence PDT.

While combination therapy appears to be safe and effective, ${ }^{11}$ comparative studies on combination therapy have not shown any improvement or reduction in vision when compared to anti-angiogenic monotherapy. ${ }^{12-14}$ Combination therapy may reduce the number of re-treatments when a PRN schedule is used, but a prospective comparison has not yet been made. The current study was organized as a pilot study to determine, in a prospective randomized fashion, the effect of combination therapy with PDT on visual outcomes, optical coherence tomography (OCT) outcomes, and total treatment burden when compared to as-needed ranibizumab treatment alone.

\section{Methods}

All patients presenting with untreated subfoveal neovascular AMD were initially considered for inclusion. Patients with pigment epithelial detachments greater than $50 \%$ of the total lesion size were excluded from entry. Patients were randomized to receive either three consecutive monthly ranibizumab injections or one ranibizumab injection combined with half-fluence $\left(25 \mathrm{j} / \mathrm{cm}^{2}\right)$ PDT. PDT treatments for occult lesions were performed off-label. Patients were monitored monthly for twelve months and re-treated PRN based on clinical discretion using standardized visual acuity testing (Early Treatment of Diabetic Retinopathy), clinical findings, and Zeiss Stratus OCT (Carl Zeiss Meditec, Inc, Dublin, CA). OCT scans included the fast macular scan pattern, and the central $1 \mathrm{~mm}$ subfield value was used to qualitatively assess foveal thickness. Scans with poor delineation of the outer and inner limiting membrane were measured manually using the calipers application on the OCT software. Patients in the ranibizumab only group were re-treated only with ranibizumab. Patients in the combined group were re-treated with combined therapy as long as the patient had not received PDT within the previous 90 days. If the patient was within the 90-day post-PDT period, the patient was only re-treated with ranibizumab. Neither physicians nor patients were masked to treatment protocol. Outcomes included changes in visual acuity; central $1 \mathrm{~mm}$ foveal subfield thickness, as measured by OCT; and number of injections. Two-tailed $t$-tests were used to compare changes in vision and foveal thickness. Chi-square tests were used to compare the differences in number of injections.

\section{Results}

Sixty patients were enrolled in the study. Fifty-six patients completed twelve months of treatment, with 27 receiving ranibizumab alone and 29 receiving combined treatment. Fourteen patients $(52 \%)$ receiving ranibizumab alone had classic lesions, compared to 18 patients (62\%) in the combined group. The average age for the ranibizumab alone group was 79.1, and the average age for the combined group was 79.3. There were a total of 31 missed visits (3.99\%), and the last-visit-carried-forward method was applied for these data points.

The mean visual acuity in the ranibizumab alone group improved from 52.9 Early Treatment of Diabetic Retinopathy letters (range, 14 to 93 letters) to 62.8 letters (range, 20 to 85 letters), which was a 9.9 letter difference (standard deviation, 23.88). Six patients (22\%) in the ranibizumab alone group lost 15 or more letters $(19,20,21,21,24$, and 35 letter loss). Nine patients (33\%) gained 15 or more letters $(19,22,24$ 32, 33, 34, 38, 55, and 63 letter gain). The mean visual acuity in the combined group improved 


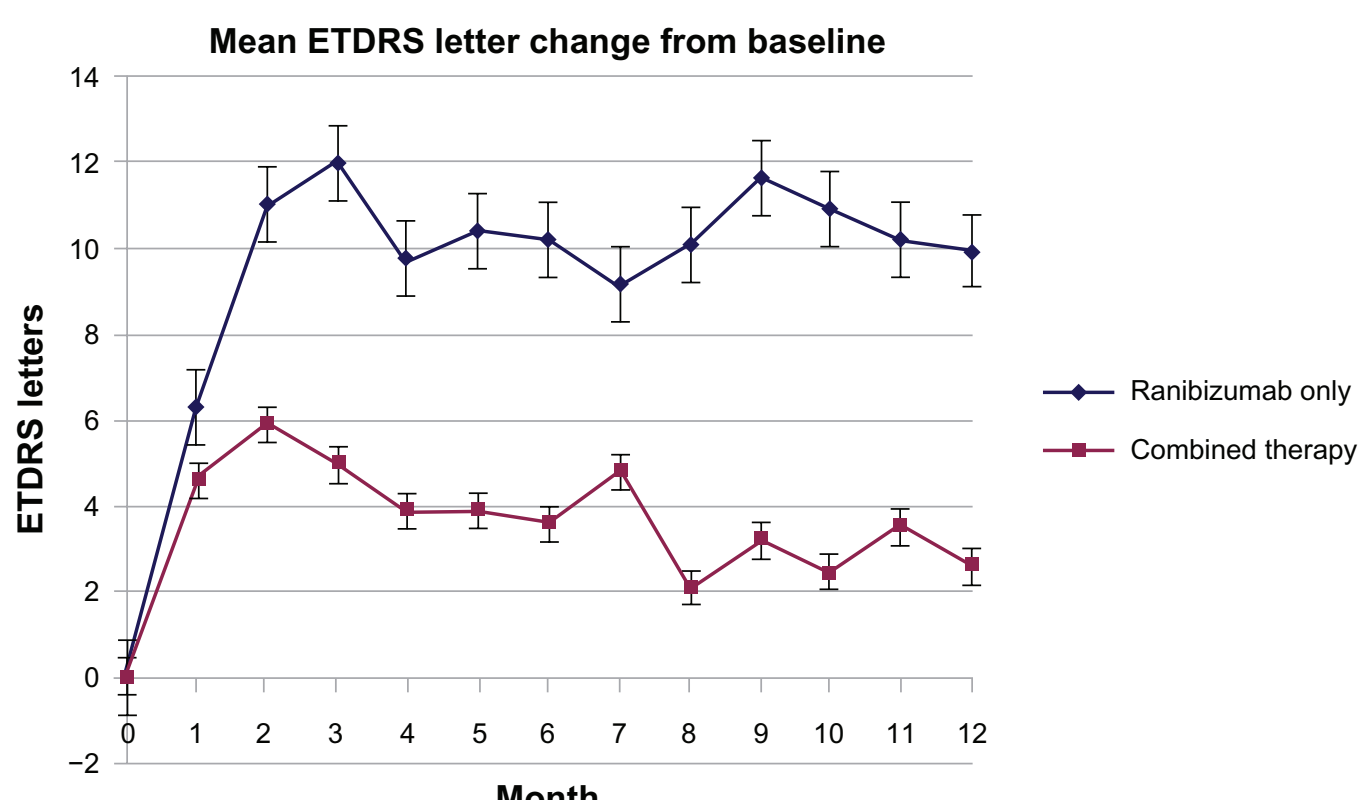

Figure I Mean change from baseline in best-corrected visual acuity by Early Treatment of Diabetic Retinopathy (ETDRS) letters at each monthly follow-up visit.

from 49.2 letters (range, five to 95 letters) to 51.8 letters (range, 15 to 82 letters) for a 2.6 letter difference (standard deviation, 18.53). Four patients (14\%) in the combined group lost 15 or more letters $(17,25,35$, and 53 letter loss). Nine patients $(31 \%)$ gained 15 or more letters $(15,16,17$, $18,23,23,23,25$, and 27 letter gain). The difference in visual acuity improvements was not significant based on a two-tailed $t$-test $(P=0.20)$. Due to the outliers in each group, a Mann-Whitney U test was performed as well. The differences were not significant with non-parametric testing $(\mathrm{U}=325 ; P=0.28)$. Figure 1 illustrates the mean changes in vision over the twelve-month study period. Figure 2 shows the percentage of patients losing less than 15 letters, while Figure 3 shows the percentage of patients gaining at least 15 letters. In a subgroup analysis of patients treated with

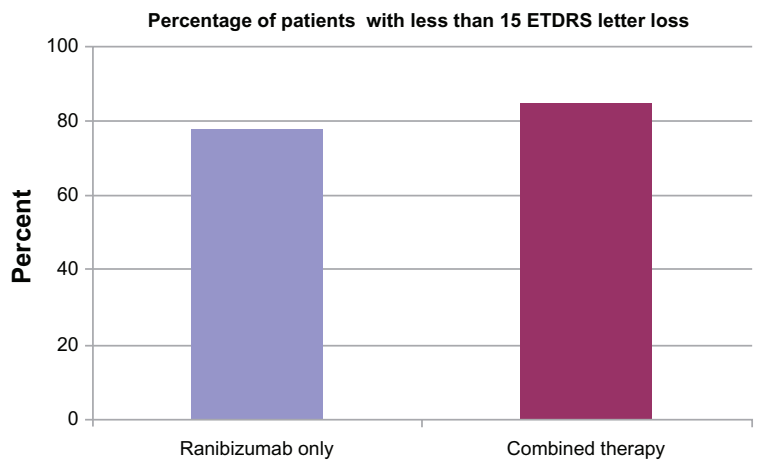

Figure 2 Percentage of patients from each treatment group with less than 15 letter (Early Treatment of Diabetic Retinopathy [ETDRS]) loss at twelve month follow-up visit compared to baseline. combination therapy, those with classic lesions improved an average of 5.7 letters, while those with occult lesions lost an average of 2.5 letters. This difference was not statistically significant $(P=0.25)$.

The mean OCT foveal thickness in the ranibizumab only group decreased from 313.6 microns (range, 151 to 635 microns) to 221.1 microns (range, 136 to 275 microns), which was a 92.5 micron difference (standard deviation, 111.26) (Figure 4A). The mean foveal thickness in the combined therapy group decreased from 320.5 microns (range, 212 to 538 microns) to 213.8 microns for a 106.7 micron difference (standard deviation 94.12) (Figure 4B). The difference was not significant based on a two-tailed $t$-test $(P=0.60)$. Figure 4A and B illustrate the mean foveal thickness and change from baseline over the twelve-month

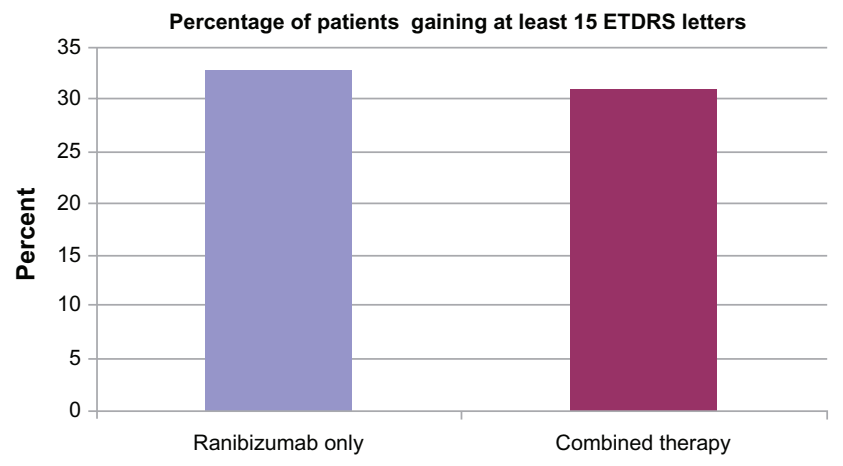

Figure 3 Percentage of patients from each treatment group gaining 15 letters (Early Treatment of Diabetic Retinopathy [ETDRS]) or more at twelve month follow-up visit compared to baseline. 


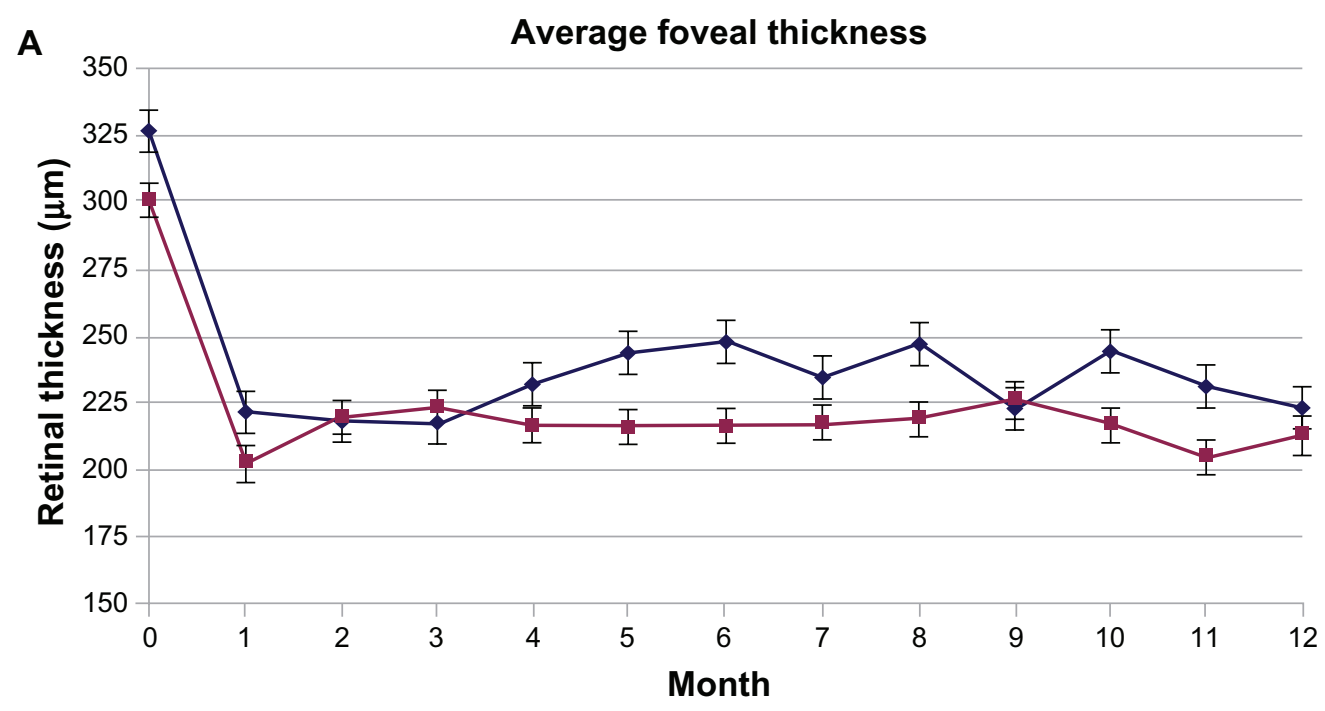

B

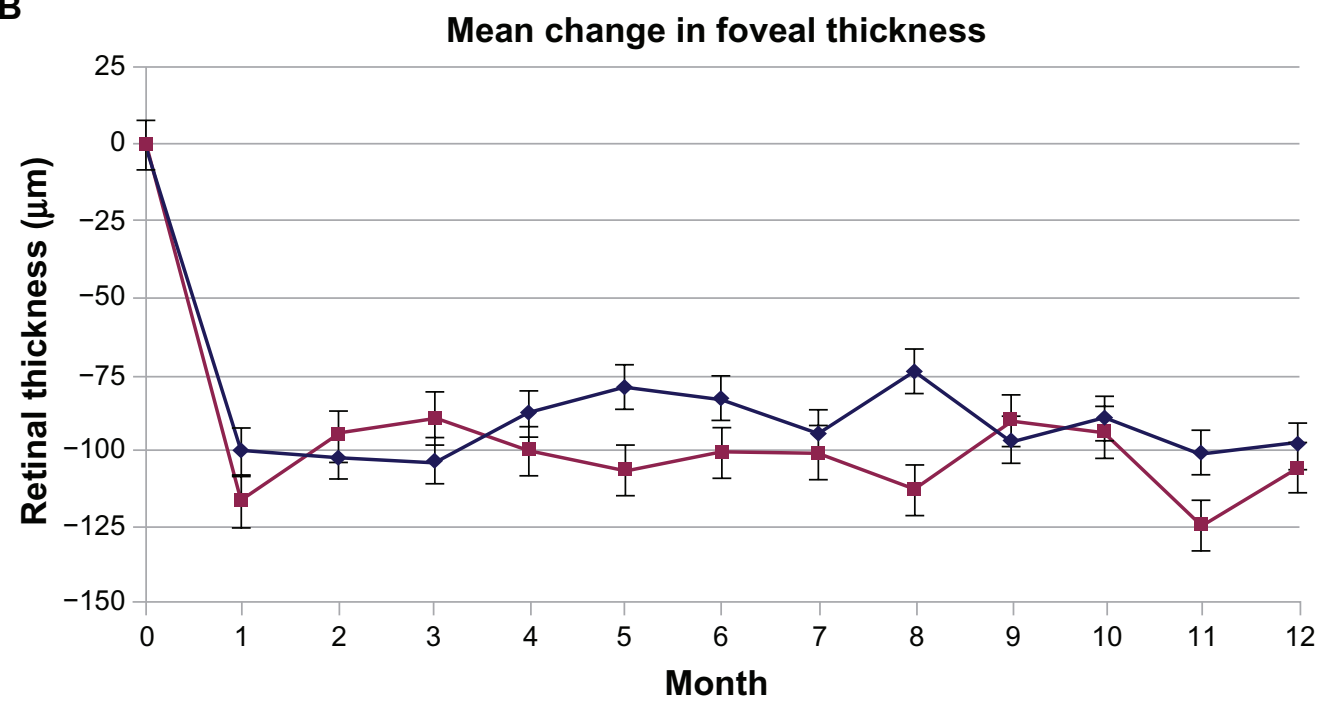

C

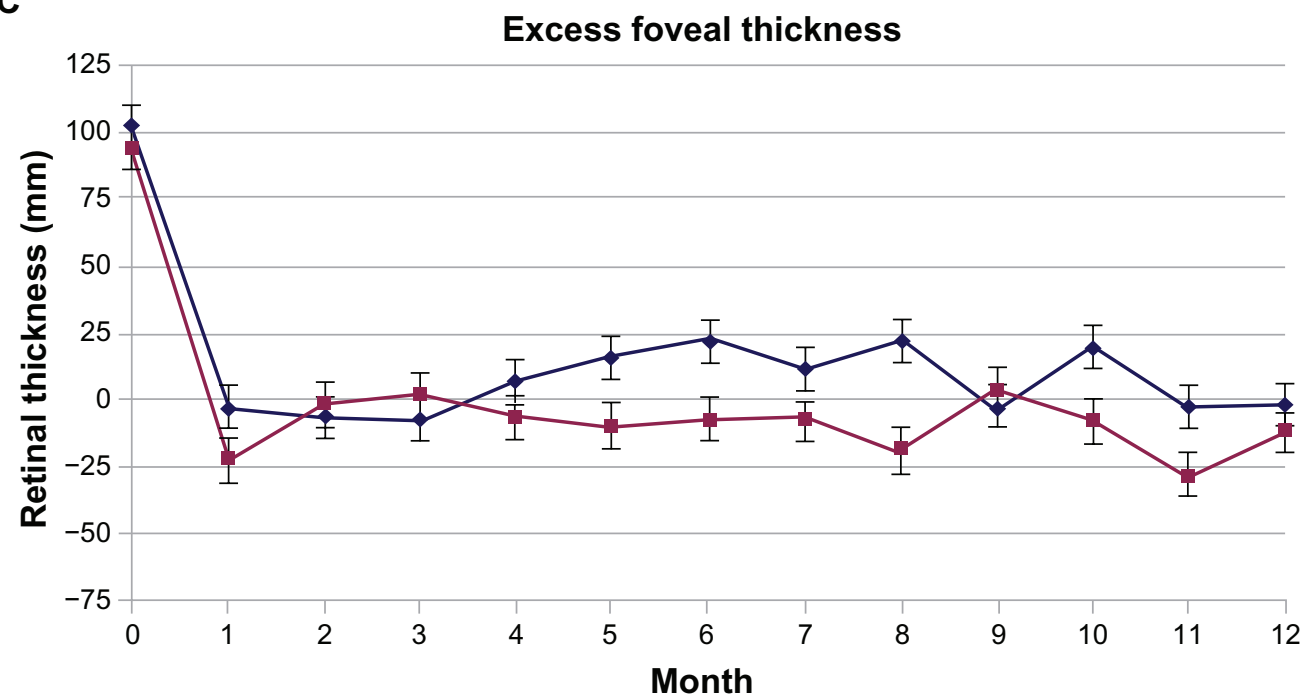

Figure 4 (A) Average foveal thickness as measured by optical coherence tomography at the central I mm subfield at each monthly follow-up visit. (B) Mean change from baseline in foveal thickness as measured by optical coherence tomography at the central I mm subfield at each monthly follow-up visit. 


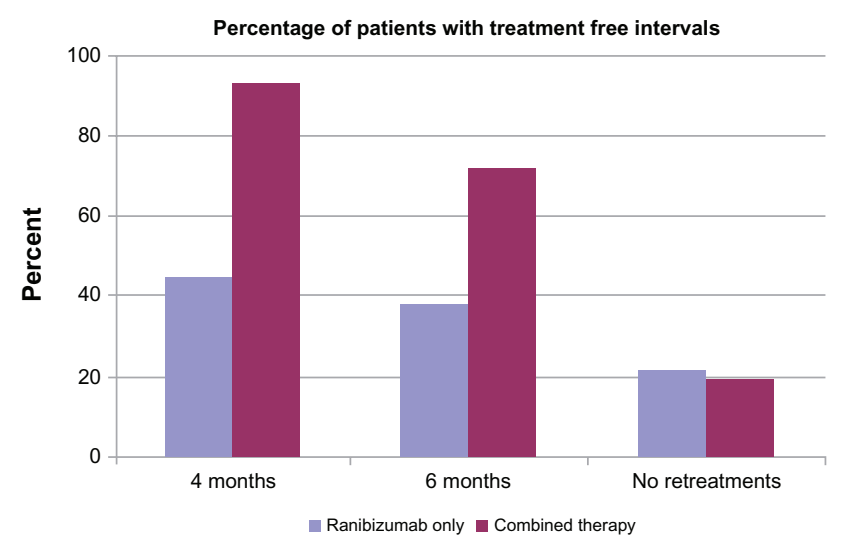

Figure 5 Percentage of patients in each treatment group with treatment free intervals.

study period, respectively. Thirteen patients $(48 \%)$ in the ranibizumab only group had subretinal fluid present on OCT at the first follow-up visit, while three patients (10\%) in the combined group had subretinal fluid present at the first follow-up visit.

The ranibizumab alone group received an average of 6.8 injections, while the combined group received an average of 3.0 injections. This difference was not significant using a chisquare test $(P=0.11)$. The number of injections equates to 3.8 PRN injections over nine months ( $42 \%$ of maintenance visits) in the ranibizumab alone group and 2.0 PRN injections over eleven months (18\% of maintenance visits) in the combined therapy group. This difference also was not significant using a chi-square test $(P=0.24)$. The percentage of patients in each group with treatment free intervals after completion of the mandatory treatments is shown in Figure 5.

\section{Conclusion}

Anti-vascular endothelial growth factor treatment remains the mainstay of therapy for wet AMD. This pilot study did not find any gross differences between the two groups. The results of this study do not support the addition of reducedfluence photodynamic therapy with verteporfin to ranibizumab treatment, but larger studies are needed to determine if the addition of reduced-fluence PDT creates small changes in outcomes. In this study, there were trends toward fewer injections and worse vision in the combination therapy group, but there were no statistically significant differences. This study is limited by the small number of patients included as well as the lack of masking. The results should be analyzed considering these limitations and the potential of a type II error.

There was considerable variability in the visual responses to therapy, both in the ranibizumab alone and the combination groups. The percentage of patients losing 15 or more letters was higher in each group than the rates reported in the ANCHOR and MARINA trials. ${ }^{1,2}$ The high variability may account for the lack of statistical significance. There were two patients in the ranibizumab only group that had remarkably large visual gains (55 and 63 letters). These patients skewed the mean visual change in favor of the ranibizumab only group. There was also a patient in the combined group that lost 53 letters, which also skewed the results in favor of ranibizumab only treatment. Whether these atypical results are a result of treatment choice or patient characteristics is unclear. The PRN maintenance regimen must also be considered as a possible cause of the high variability. In the recent retrospective report by Rudnisky et al comparing variable regimens of bevacizumab monotherapy and combination therapy with PDT, the rates of vision loss were $25.9 \%$ and $19.9 \%$, respectively. ${ }^{12}$ However, these are in contrast to the results of the PrONTO study. The Comparison of AMD Treatment Trials (CATT) should determine the benefits of fixed and variable maintenance regimens.

Another possible explanation for the visual acuity results is the inclusion of occult lesions in the combination therapy group. While this study was not designed or powered for appropriate statistical examination, a discussion of the differences is still warranted. The preferential benefit of PDT with classic lesions over occult lesions has been well established. Ranibizumab, however, seems to affect classic and occult lesions similarly. In this study, patients with occult lesions receiving combination therapy actually lost vision on average. Even patients with classic lesions did not have the mean visual gain garnered by ranibizumab monotherapy.

As shown in Figure 1, the visual improvements were nearly identical at one month. However, at month two, the ranibizumab alone group continued to have a mean improvement in visual acuity, while the combined group only maintained the initial gain. This effect may be an anomaly due to the high variability in treatment response. Another possibility is a treatment response not appreciated by OCT foveal thickness measurements. While the changes in OCT foveal thickness remained very similar at each follow up visit, 13 patients in the ranibizumab only group had subretinal fluid at the first follow-up visit compared to three patients in the combined therapy group. All patients in the ranibizumab group received a mandatory second injection at month one, while the combined group received treatment only as needed. An additive effect of the second ranibizumab injection cannot be ruled out, especially considering the number of patients 
with residual subretinal fluid at follow up. Residual fluid at month one is not unusual, however, as shown by Avery et al. ${ }^{15}$ According to this report, 63\% patients receiving monthly bevacizumab had residual fluid one month after the initial injection. It must be noted, though, that there may be a difference in residual fluid rates between bevacizumab and ranibizumab. Another possibility is a negative effect of PDT. Even though the combination group only received halffluence PDT, the possibility of toxicity still remains.

Adding a steroid medication to combination therapy may mitigate the potential deleterious effects of PDT. "Triple therapy" including anti-vascular endothelial growth factor, PDT, and steroid has shown some success in the treatment of wet AMD. ${ }^{16-18}$ The vaso-occlusive effects of PDT may incite inflammation in the surrounding tissue. Therefore, steroid anti-inflammatory medications may reduce ancillary damage to normal tissues. Both triamcinolone and dexamethasone have been proposed as adjuncts, but dexamethasone may have some specific advantages as the steroid of choice. Augustin used dexamethasone in his investigations for reasons of both safety and efficacy. ${ }^{16,18}$ Dexamethasone has a short half-life, which eliminates the risk of a delayed increase in intraocular pressure. Dexamethasone has antiproliferative, antifibrotic, and antimigration properties.

In summary, this study did not demonstrate any statistically significant advantage to the addition of half-fluence PDT to ranibizumab therapy for wet AMD. However, the potential remains for triple therapy to provide some benefit over antivascular endothelial growth factor monotherapy.

\section{Disclosure}

The authors have no propriety interest in any of the products discussed in this manuscript. This study was supported by Novartis Pharmaceuticals. P Williams has commercial relationships with Alcon, Ista, Allergan, Regeneron, and Novartis; D Callanan has commercial relationships with Alcon, Allergan, Bausch and Lomb, and Novartis; Wayne Solley has commercial relationships with Alcon; Tom Aaberg has no commercial relationships; DJ Pieramici has commercial relationships with Genentech, Novartis, QLT, and Ophthotec; RL Avery has commercial relationships with Alcon, EyeTech, Genentech, Novartis, QLT, OSI/Pfizer, Neovista, and Regeneron.

\section{References}

1. Brown DM, Kaiser PK, Michels M, et al. Ranibizumab versus verteporfin for neovascular age-related macular degeneration. $N$ Engl J Med. 2006; 355:1432-1444.
2. Rosenfeld PJ, Brown DM, Heier JS, et al. Ranibizumab for neovascular age-related macular degeneration. $N$ Engl J Med. 2006;355: 1419-1431.

3. Fintak DR, Shah GK, Blinder KJ, et al. Incidence of endophthalmitis related to intravitreal injection of bevacizumab and ranibizumab. Retina. 2008;28:1395-1399.

4. Regillo CD, Brown DM, Abraham P, et al. Randomized, doublemasked, sham-controlled trial of ranibizumab for neovascular agerelated macular degeneration: PIER Study year 1. Am J Ophthalmol. 2008;145:239-248.

5. Fung AE, Lalwani GA, Rosenfeld PJ, et al. An optical coherence tomography-guided, variable dosing regimen with intravitreal ranibizumab (Lucentis) for neovascular age-related macular degeneration. Am J Ophthalmol. 2007;143:566-583.

6. Lalwani GA, Rosenfeld PJ, Fung AE, et al. A variable-dosing regimen with intravitreal ranibizumab for neovascular age-related macular degeneration: year 2 of the PrONTO Study. Am J Ophthalmol. 2009; 148:43-58.

7. Treatment of Age-Related Macular Degeneration with Photodynamic Therapy (TAP) Study Group. Photodynamic therapy of subfoveal choroidal neovascularization in age-related macular degeneration with verteporfin: one-year results of 2 randomized clinical trials - TAP report. Arch Ophthalmol. 1999;117:1329-1345.

8. Treatment of Age-Related Macular Degeneration with Photodynamic Therapy (TAP) Study Group. Photodynamic therapy of subfoveal choroidal neovascularization in age-related macular degeneration with verteporfin: two-year results of 2 randomized clinical trials - TAP report 2. Arch Ophthalmol. 2001;119:198-207.

9. Arnold JJ, Blinder KJ, Bressler NM, et al. Acute severe visual acuity decrease after photodynamic therapy with verteporfin: case reports from randomized clinical trials - TAP and VIP report no 3. Am J Ophthalmol. 2004;137:683-696.

10. Azab M, Boyer DS, Bressler NM, et al. Verteporfin therapy of subfoveal minimally classic choroidal neovascularization in age-related macular degeneration: 2-year results of a randomized clinical trial. Arch Ophthalmol. 2005;123:448-457.

11. Schmidt-Erfurth U, Wolf S; PROTECT Study Group. Same day administration of verteporfin and ranibizumab $0.5 \mathrm{mg}$ in patients with choroidal neovascluarization due to age related macular degeneration. Br J Ophthalmol. 2008;92:1628-1635.

12. Rudnisky CJ, Liu C, Ng M, Weis E, Tennant MT. Intravitreal bevacizumab alone versus combined verteporfin photodynamic therapy and intravitreal bevacizumab for choroidal neovascularization in agerelated macular degeneration: visual acuity after 1 year of follow-up. Retina. 2010;30:548-554.

13. Kaiser PK; Registry of Visudyne AMD Therapy Writing Committee, Boyer DS, et al. Verteporfin photodynamic therapy combined with intravitreal bevacizumab for neovascular age-related macular degeneration. Ophthalmology. 2009;116:747-755

14. Smith BT, Dhalla MS, Shah GK, Blinder KJ, Ryan EH Jr, Mittra RA. Intravitreal injection of bevacizumab combined with verteporfin photodynamic therapy for choroidal neovascularization in age-related macular degeneration. Retina. 2008;28:675-681.

15. Avery R1, Pieramici DJ, Rabena, MD, Castellarin AA, Nasir MA, Giust MJ. Intravitreal bevacizumab (Avastin) for neovascularization age-related macular degeneration. Ophthalmology. 2006;113: 363-372.

16. Augustin A. Triple therapy for age-related macular degeneration. Retina. 2009;29:S8-S11.

17. Yip PP, Woo CF, Tang HH, Ho CK. Triple therapy for neovascular age-related macular degeneration using single-session photodynamic therapy combined with intravitreal bevacizumab and triamcinolone. $\mathrm{Br}$ J Ophthalmol. 2009;93:754-758.

18. Augustin AJ, Puls S, Offermann I. Triple therapy for choroidal neovascularization due to age-related macular degeneration: verteporfin PDT, bevacizumab, and dexamethasone. Retina. 2007;27:133-140. 
Clinical Ophthalmology

\section{Publish your work in this journal}

Clinical Ophthalmology is an international, peer-reviewed journal covering all subspecialties within ophthalmology. Key topics include: Optometry; Visual science; Pharmacology and drug therapy in eye diseases; Basic Sciences; Primary and Secondary eye care; Patien Safety and Quality of Care Improvements. This journal is indexed on

PubMed Central and CAS, and is the official journal of The Society of Clinical Ophthalmology (SCO). The manuscript management system is completely online and includes a very quick and fair peer-review system, which is all easy to use. Visit http://www.dovepress.com/ testimonials.php to read real quotes from published authors. 